\title{
CRITICAL INCIDENTS AND CRITICAL INCIDENT STRESS \\ MANAGEMENT (CISM) - AN EMPLOYEE ASSISTANCE \\ PROGRAMME (EAP) PERSPECTIVE
}

\section{Lourie Terblanche, André van Wyk}

\section{INTRODUCTION}

Crime statistics for South Africa indicate that "[r]ecorded crime increased by $15 \%$ between 1994 and 1999, with an average year-on-year increase of 3\% during this time" (Altbeker, 2002:7). According to Altbeker (2002:10), 217 out of every 100000 people in Johannesburg and 148 out of every 100000 people in Pretoria were raped during 1999. The number of assaults per 100000 people was even higher, namely 923 people in Johannesburg and 590 in Pretoria. Car hijacking increased by 29\% a year between 1994 and 1999. In Gauteng murder increased by $2 \%$ and rape by $4 \%$ annually between 1994 and 1999. Despite the fact that these figures are now decreasing, they are still staggering: "National and Provincial police crime figures indicate that crime to a certain extent, (sic) levelled off in the course of 2002. Murder rates continue to decline, as does vehicle theft. However, the trends for car hijacking are less positive" (Leggett, 2003:17).

More recent statistics provided by the SAPS show murder to be still as high as 30.9 persons and rape 94.9 persons per 100000 in South Africa in 2011/12.

These statistics indicate that many people are directly or indirectly affected, either as victims, family members, friends or colleagues. Victims are also employees, and if the above statistics were applied to the South African workforce, it could be assumed that incidents such as the above do have a major impact on the workplace and do result in great economic loss.

Even though employees may not admit that they are traumatised, certain symptoms of their distress could manifest in the workplace, indicated by absenteeism, poor concentration, careless mistakes, hypersensitivity and conflict with co-workers, irritability, aggression, social withdrawal, depression and physical symptoms such as headaches, stomach aches and diarrhoea (Sonderup, 1996:12).

\section{DEFINING A CRITICAL INCIDENT}

A critical incident is defined as "an event that is extraordinary and produces significant reactions for the intervening person. It may be so unusual that it overwhelms the natural abilities of people that have to cope with difficult situations" (Lewis, 1996:15). A critical incident may lead to stress, burnout, or even post-traumatic stress disorder (PTSD), which can be experienced almost immediately or could be delayed for days, weeks or months. According to Lewis (1996:18), a critical incident can lead to a range of physical, cognitive and emotional reactions. Physical reactions include fatigue, dizziness, nausea, and sleep and appetite disturbances. Cognitive reactions may include mental confusion, memory impairment, difficulties with decision-making and intrusive thoughts. Emotional reactions may include fear, anxiety, depression, grief and 
irritability. These reactions have a significant impact on the work life and performance of the victim, and may even have the same impact on people close to the victim.

A critical incident, according to O'Connor and Jeavons (2002:53), is an extraordinary event that has the potential to cause unusually strong emotional reactions.

When an individual is involved in an event that takes place in a specific manner, under particular circumstances and at a given point in time, various characteristics of the situation turn the event into an experience of powerlessness, disruption and discomfort. Characteristics of the event and its context, which include the severity of stress, are highly decisive factors in the process of coping with traumatic stress. Most critical incidents are unexpected, and the onset of the event is almost always sudden and not anticipated. Such experiences challenge the individual's ability to accurately assimilate and comprehend the experience; such an event can devastate even the most secure person or family (Kleber \& Brom, 1992:40).

The view expressed by Yehuda (2002:108) sum up this matter: "The defining characteristic of a traumatic event is its capacity to provoke fear, helplessness, or horror in response to the threat of injury or death."

\section{RISK FACTORS IN TRAUMATISATION AS A RESULT OF A CRITICAL INCIDENT}

Van der Kolk and McFarlane (1996:3) confirm that experiencing trauma is an essential part of being human. However, certain factors play a part in the victim's reactions to a critical incident, a point which is expanded by Friedman (2003:21), who states that research indicates that the following pre-trauma risk factors may influence the individual's response to a critical incident:

- The possibility of women developing PTSD is twice as likely as for men;

- People under the age of 25 years are more vulnerable;

- People with no tertiary education are more at risk;

- Childhood adversity, such as deprivation and divorce, may have an effect on a person's coping strategies;

- Previous exposure to critical incidents in childhood; for example, child abuse, rape, war or motor vehicle accidents;

- Prior psychiatric disorders and family history of psychiatric disorders;

- Attention deficit disorder and hyperactivity disorder;

- Previous exposure to a critical incident as an adult;

- Adverse life events, such as divorce, loss of job or financial problems;

- Physical health problems such as asthma, heart disease, cancer or back problem.

O'Brien (1998:93) mentions that post-traumatic illness or the reaction to a critical incident should be short-lived and would only become chronic if there are pre-existing 'maladjustment' or vulnerability factors. A pre-existing mental condition is apparently a very successful predictor of PTSD. In studies by Greenwald and Leitenberg (in O'Brien, 
1998:05), it was found that the highest rates and also the widest variation of PTSD were associated with female survivors of sexual abuse, rape and physical abuse. O'Brien (1998:95) further states that a person's personal view of life and their perception of whatever happens to them are of major importance as predisposing factors in the development of PTSD after exposure to a critical incident. O'Brien furthermore points out that certain personality traits, especially neuroticism, are associated with the development of PTSD following a critical incident. Family instability, academic difficulties, a childhood history of abuse and neglect, a history of mental illness and illicit drug use are pre-trauma risk factors that have to be considered in the development of PTSD, but they ostensibly have less effect than exposure to the critical incident itself (O'Brien, 1998:97-98). Heinrichs, Wagner, Schoch, Soravia, Hellhammer and Ehlert (2005:2276-2277) support O'Brien's views as they state that specific personality traits may constitute markers of vulnerability to the development of psychopathological symptoms after trauma exposure. They elaborate on this by specifying the importance of early identification of pre-existing risk factors to provide effective prevention for individuals at risk.

\section{SITUATIONAL FACTORS AS RISK FACTORS IN TRAUMATISATION}

Certain situational and personal predisposing factors (Lewis, 1996:52-57) may affect the victim's reaction to a critical incident and may influence the development of PTSD. These are indicated below.

\section{Warning}

The less of a warning received prior to the incident, the more profound the emotional impact of a critical incident. A sudden and unexpected critical incident, for example, an earthquake, means that there is no time to prepare emotionally for the possible outcome, therefore risking traumatisation as a result.

\section{Nature of the crisis}

Lewis (1996:52) and Friedman (2003:24) are of the opinion that a victim's emotional response differs in reaction to a man-made situation and a natural disaster. These authors pointed out that in the case of a man-made critical incident where there is interpersonal violence, for example, rape, physical attack or torture, it is more likely to cause trauma than in the case of an impersonal event such as a natural disaster. Victims of crime often go through stages of self-blame and guilt for having been unable to prevent the critical incident. The feelings of blame and responsibility may also be directed at others.

\section{Severity of the crisis}

According to Lewis (1996:53), positive correlations exist between the severity of a critical incident and the reactions of people involved. According to Lewis, severity is difficult to define. Different individuals perceive a critical incident differently, and what may be a severe incident in one person's view may seem a minor incident in another's. It is, however, essential to remember that the critical incident and its nature are not the most important things, but that it is rather people's different perceptions of the incident and the associations it has for them that count. Amstadter and Vernon (2008:392-396) 
confirmed the importance of understanding the different emotions elicited by different types of traumatic events. Friedman (2003:22) maintains that the greater the severity ('dose') of the critical incident and the magnitude of trauma exposure, the greater the likelihood of the individual being traumatised. The most severe trauma often includes a perceived life threat or a serious injury.

\section{Physical proximity}

The closer the victims are to the incident, the stronger their reaction will be (Lewis, 1996:53). When someone is directly affected by a critical incident, the traumatic reaction is potentially more severe. If someone knows the victims of a critical incident, or is closely related to them, the risk of secondary or vicarious trauma to the person(s) knowing the victim is increased.

\section{Feelings of guilt}

Participation in atrocities, or being responsible for harm to others, as either a perpetrator or a witness, poses a risk for being severely affected by a critical incident (Friedman, 2003:24).

\section{Time}

The longer the duration of the critical incident, the greater the risk of being traumatised (Friedman, 2003:25).

\section{Psychological proximity}

When a critical incident has a personal impact on the victim, there is a greater risk of $\mathrm{him} / \mathrm{her}$ not coping with it. When someone's child, or another child of similar age, is the victim of a critical incident, parents tend automatically to identify with the victim, which compounds the possibility that there will be secondary trauma (Lewis, 1996:54).

\section{Concurrent stressors}

According to Lewis (1996:55), stress is cumulative. If there are many other losses, changes, or transitions in an individual's life, another crisis (especially a traumatic one) may be the last straw. People under stress tend to be more prone to accidents, illnesses or other crises, and their capacity for resolving the latest one is diminished. This may become a vicious cycle, whereby stress leads to diminished capacity to cope with trauma, which may lead to more stressful events, which further diminishes the person's ability to cope.

\section{POST-TRAUMA RISK FACTORS}

Friedman (2003:27) also refers to the following post-trauma risk factors:

- In the case of poor social support, or a limited support network, the likelihood of being traumatised or developing PTSD is greater;

- Immediate traumatic reactions, such as dissociation or avoidance symptoms, may be the result of a severe and sudden impact of a critical incident. Immediate reaction poses a greater risk for the development of PTSD at a later stage. 
In terms of post-trauma risk factors, Lewis (1996:11) indicates certain factors that could encourage the development of resilience after a critical incident, especially in children. These factors include the following:

- The availability of a close, loving relationship with a supportive, available caregiver;

- A stable, supportive family environment, which gives a child structure, clear rules and good supervision;

- Sources of emotional support outside the family, for example, community or religious leaders, neighbours, teachers or peers;

- Role models who display positive problem-solving skills and who themselves may have lived through a critical incident.

Although these factors focus on how resilience can be encouraged in children after a critical incident, they are also applicable to adults affected by a critical incident. The availability of a loving, supportive relationship, the structure of a family, the support of religious or community leaders and positive role models may help to minimise the risk of a critical incident and prevent the development of PTSD.

\section{REACTIONS TO A CRITICAL INCIDENT}

The way that people experience a critical incident varies from person to person and from one event to another, as differences in the individual variables affect the ways in which stressful events are perceived. Trauma in itself can alter personal functioning in pathological ways and can influence life-course development (Wilson, 1989:12). It must also be noted that trauma never occurs in a contextual vacuum. Critical incidents have the capacity to shatter the survivors' fundamental assumptions about themselves and their inner world, which forces them to confront their own vulnerability (JannofBullman, 1997:56). It is important to understand the ways in which a long-term response to a traumatic experience is shaped by a variety of social, psychological and environmental processes, which interact in complex ways to co-determine and construct an experience of trauma (Tedeschi \& Calhoun, 1995:24).

Bisson (1995:718) maintains that any traumatic event, including a violent crime, may precipitate an acute psychological response. Characteristic features of this response include fear, anger, recurrent distressing thoughts, guilt, depression, anxiety, bad dreams, irritability and generalised hyper-arousal, immediately after a violent crime, should be considered normal (Amstadter \& Vernon, 2008:392; Bisson, 1995:718).

However, Bisson (1995:718) also indicates that the response to violent crime can become problematic at any stage. He further acknowledges that a severe initial response often represents an acute stress disorder. Over time other conditions such as PTSD, anxiety disorders, depressive disorders and substance abuse/dependence may develop. These conditions can have devastating effects on victims' lives and markedly affect their functioning at the personal, social and occupational levels. However, along this wide spectrum of reactions to traumatic events, there is positive evidence that variables other than the dimensions of the trauma itself do influence the outcome. Bisson (1995:719) proposes that acute stress disorder, a psychiatric history, a family psychiatric history, 
lack of social support and high levels of "neuroticism" are all possible factors associated with exacerbation of the experience of trauma and an increased rate of PTSD and PTSDlike symptoms. Individuals exposed to highly stressful events and trauma are likely to experience a constellation of distressing emotions. Although the specific patterns vary with individuals, it is correct to say that unpleasant emotional states are almost bound to occur. In part this distress may be due to a sense of hopelessness that is produced when certain events are acknowledged to be irreversible and unchangeable. Moreover, if a trauma is of human agency, the incidence of PTSD is higher than in cases where the trauma is of natural origin (Tedeschi \& Calhoun, 1995:24). Jannof-Bullman (1997:57) claims that, in essence and in contrast with our basic assumptions, trauma is the abrupt disintegration of the victim's inner world. The survivor's innate trust and confidence are shaken. Consequently, thoughts and images of callousness and meaninglessness may arise.

Findings by MacGregor (1998:41) concur with the above-mentioned studies supporting the notion that traumatic events have negative outcomes. It was found that reactions like telling victims that they have been "lucky" are likely to be perceived negatively and will have the primary effect of invalidating the traumatic nature of the experience and their response to it.

When emotional functioning has been negatively affected after an experience of a critical incident, depression is regarded as one of the more common reactions, and is said to be more likely to develop when a significant loss is involved. The study by MacGregor (1998:41-42) acknowledges that depression, especially major depression, interconnects with PTSD. Shalev, Freedman, Peri, Brandes, Sahar, Orr and Pitman (1998:638) evaluated the onset, overlap and course of PTSD and major depression following a traumatic experience. The results of the study mentioned by the latter group of authors show that major depression and PTSD set in soon after a critical incident. In addition, patients with a diagnosis of PTSD had comparable recovery rates: 63 survivors (29.9\%) met the criteria for PTSD at one month after the incident and $37(17.5 \%)$ had PTSD four months after the event. On the other hand, forty subjects $(19.0 \%)$ met the criteria for major depression one month after a critical incident and 30 (14.2\%) had major depression after four months. Co-morbid depression - referring to more than one condition which is experienced simultaneously - occurred in $44.5 \%$ of PTSD patients after one month and in $43.2 \%$ at four months. Co-morbidity was associated with greater severity of symptoms and lower levels of functioning. Prior depression was associated with a higher prevalence of major depression after exposure to trauma. Shalev et al. (1998:639) conclude that major depression and PTSD are independent consequences of traumatic events, have similar prognoses, and interact to increase distress and dysfunction. The mentioned study proposes that both major depression and PTSD should be targeted with early treatment interventions and neurobiological research.

Often a person affected by a critical incident has to face the after-effects for a long period, as confirmed by Kleber and Brom (1992:2): "When the event has passed, it does not mean that the experience is over for those involved". Van der Kolk (1991:3) describes the response to a traumatic event as a phasic reliving and denial of the event 
with alternating intrusive and numbing responses. The intrusive responses usually involve hyper-reactivity, explosive aggressive outbursts, startled responses and intrusive recollections in the form of nightmares and flashbacks, and enactment of situations reminiscent of the trauma. The numbing response after a critical incident usually consists of emotional constriction, social isolation, retreat from family obligations and a sense of estrangement. Common responses to critical incidents may include various forms of re-experiencing and avoidance (Carlson, 1997:43).

According to Schulz, Van Wijk and Jones (2000:29), someone who has experienced a critical incident and who is traumatised by the event repeatedly replays mental reminders of the incident, such as a smell, a sight or a sound. According to Schulz et al. (2000:30), the experience of the replay can be so severe in certain cases that the person feels and acts as if he or she is literally experiencing the critical incident. To reexperience such an incident usually involves the cognitive, affective, behavioural and psychological faculties of the person concerned.

The critical incident activates certain processes for the individual, the first of which is usually the emotional response of shock. Shock is characterised by numbness, denial of the incident, sometimes withdrawal and, at times, hysteria. After the initial shock, normal emotional reactions such as anger, depression, sobbing, even praying and bargaining with God follow (Schulz et al., 2000:31).

After the emotional reactions, the behavioural processes start to play their part. According to Schulz et al. (2000:32), the behavioural processes are initial attempts to cope with the reality of loss and what has happened. This might involve going back to work, disposing of a lost one's clothes or having sex for the first time after being raped. These attempts would probably be painful and unsatisfactory, and it would take time to restore these behavioural processes to what they were before the critical incident. The final stage of these reactions is the cognitive or intellectual processes, whereby an individual would start to think and reason about what has happened to him or her. The person now has to reframe his or her experience in order to reach a stage of acceptance, adjustment and healing.

Arriving at the stage where the individual can adjust to and accept the critical incident usually requires a long and painful journey. During this time the individual is subjected to re-living the incident on the cognitive, affective, behavioural and physical levels. Reexperiencing the incident can be as painful as the actual incident. Owing to the pain and discomfort caused by a critical incident, the earliest response is a general feeling of numbness. This is a form of avoidance that helps the individual adjust to the severity of the incident, which usually threatens their psychological wellbeing, as was confirmed by Carlson (1997:47): "Avoidance serves the purpose of protecting the individual from exposure to reminders of the traumatic event". Cognitive avoidance can involve the person putting the critical incident or reminders of it out of his or her mind, or it can mean the distortion of the perceptions or even amnesia. Affective avoidance of a critical incident is commonly experienced as a feeling of emotional numbness. Behavioural 
avoidance typically means avoiding reminders of the incident. This includes avoiding situations, places or people associated with the critical incident (Carlson, 1997:47).

\section{EFFECT OF A CRITICAL INCIDENT ON FAMILY AND RELATIONSHIPS}

Research on trauma and its effects not only focuses on the victim's experience of a critical incident and how he or she is affected, but also confirms the symptoms of PTSD and its psychological repercussions on other family members, i.e. a spouse or child who might be responding strangely because he or she might not know how to support the actual victim of the traumatic incident. The marital dyad, the nucleus family and even the extended family are also possibly affected by the victimisation of one of its members, which suggests that traumatic events have a much wider systematic impact than simply that on the individual in isolation. Family members appear to suffer anxiety and bereavement, and their lives may be disrupted as a result of injury to their loved one. The family system should therefore be recognised in the recovery process (Engelbrecht, 1997:109; Figley, 1994:23). Schulz et al. (2000:139-140) add to this that the relationship with significant others may be affected in various ways as a result of exposure to incidents that cause post-traumatic stress.

Brende and Goldsmith (1991:121) propose a post-traumatic family victimisation cycle. According to their findings, there is a cycle of post-traumatic victimisation, which can fragment a family's functioning. The phases of the process include the original traumatic event, which often leads to alienation and isolation of family members, with anger becoming the predominantly expressed emotion. Family shame, as well as fragmentation of the family system, seems to develop as the result of a sudden, shattering tragedy, with few couples being able to survive the impact. Finally, triggering events can provoke responses that may cause repetition of the symptoms experienced previously.

It appears that trauma has the capacity to seriously affect the levels of functioning within the family. Child-parent relationships also seem to be directly influenced by the experience of trauma. Sack, Clarke and Seeley (1995:1160) considered the rates of psychological distress in two generations of Cambodian refugees living in the western United States. PTSD was found to be significantly related across parent-child generations, where parents were more likely to report an earlier onset of PTSD symptoms. This study suggests that PTSD may cluster in families. Whether this phenomenon is caused by a genetic susceptibility to trauma requires further research, according to their study (Sack et al., 1995:1161).

De Vries, Kassam-Adams, Cnaan, Sherman-Slate, Gallagher and Winston (1999:1294) support the notion that trauma is a family experience, with the family members' reactions to the trauma being closely interwoven and interrelated. Their study estimated the prevalence of PTSD in traffic-injured children and their parents, and identified risk factors for PTSD development. Twenty-five per cent of the children and $15 \%$ of the parents suffered diagnosed PTSD, but only $46 \%$ of the parents of affected children sought help in any form (including from friends) for their child and only $20 \%$ of affected parents sought help for themselves. These results reveal that PTSD in children and their 
parents is a common yet overlooked consequence of paediatric traffic-related injury with prevalence rates similar to those found in children exposed to violence. De Vries et al. (1999:1295) suggest that paediatric trauma patients, as well as their significant others, should be screened for PTSD and referred for treatment where appropriate. This indicates that the experience of trauma may very well be maintained within the family context. It appears, then, that the family may act as a double-edged sword in posttraumatic reactions; on the one hand, the family provides a valuable resource and source of social support to traumatised individuals but, on the other hand, the family may support and maintain pathological reactions to traumatic experiences.

According to Smith (2005:1), family members who experience a shared trauma often become closer and appreciate each other more. Examples of traumatic events include life threatening car accidents, bush fires, floods, sudden illness or traumatic death in the family, crime or violence. A critical incident can change a person's attitudes, beliefs, feelings and behaviour.

Critical incidents have an effect on the family's functioning and dynamics even years after the incident. According to Smith (2005:1-3), family dynamics can be affected in the short, medium and long term.

\section{INFLUENCE OF CRITICAL INCIDENTS IN THE WORKPLACE}

Critical incidents do have a direct impact on the workplace as a result of the response on the individual experiencing the trauma. Ribner (1993:333) mentions that "because of the critical importance of work, any disruption in the homeostasis of the workplace may have a profound impact on the worker". The emotional impact of an incident can be critical "when dreams and way of life are threatened with extinction" (Ribner, 1993:333).

Most systems of which individuals form a part are constantly in a state of change, which allows for growth and development. At the same time, the system requires structure and stability, as indicated by Compton and Galaway (1984:123): "at the same time that a system is constantly in a state of change, it must maintain a dynamic equilibrium". Problems occur within the system owing to its inability to cope with the stress and tension created by the change. As a result, the system is unable to maintain order and functions in a state of chaos. Problems seem to be the system's way of responding to the overwhelming chaos.

Because the boundaries of the system are semi-permeable, they sustain change within the system. It is these same boundary characteristics, however, that allows one system to influence another. It is therefore presumed that changes in the work social system influence the family social system, and problems within the family social system influence the work social system. The same holds true for all of the other systems of which individuals form a part. An employee, as part of the work system, therefore cannot be adequately understood in isolation from his/her roles within the other social systems to which he/she subscribes. 
It is important to acknowledge that changes may be positive or negative. For this reason the employee's general life satisfaction and happiness have a positive impact on his/her work; similarly an employee's general discontentment with life and his/her resentment influence his/her work performance negatively. Simply having good working conditions, therefore, cannot guarantee a problem-free production environment. According to the authors, it would be impractical to expect employees to leave their personal problems at home, and it would be naive to believe that the problems resulting from the workplace will remain isolated from the employee's personal life.

Bruce (1990:37) mentions that "no employee stands alone, unchanged by the events and actions around him or her. Employees have lives outside the world of work. In those lives family and friends make demands on time and energy". The influence of social problems experienced by employees within their other social systems on the workplace is further explored below. According to Kessler and Stang (2006:20), "employees who have suffered even temporary mental or emotional illness may have difficulty meeting his job requirements". The influence of social problems usually manifests itself in a range of different reactions because of our individual responses to stress and our own uniqueness. The resulting impact on the workplace, however, can be narrowed down to the following five broad categories: poor work attendance, drop in productivity, deteriorating interpersonal relationships, health issues and societal issues.

\section{THE EAP'S ROLE IN MANAGING CRITICAL INCIDENTS IN THE WORKPLACE}

Traditionally, employee assistance programmes (EAPs) will be the first port of call if an employer has a crisis, like the death of a spouse or a child, in the workplace. The majority of EAP service providers have a programme in place to address workplace trauma. Stephenson and Schneider (2006:35) mention that the demand on EAPs has increased dramatically in terms of addressing emotional and mental health demands of the customer organisations and their employees in response to large-scale natural or man-made disasters. This response is often a generic response and usually includes critical incident stress debriefing.

Vineburgh, Ursano, Gifford, Benedek and Fullerton (2006:14) mention that, with events such as 9/11 (the terrorist attack on the Twin Towers in New York on 11 September 2001), Hurricane Katrina in New Orleans in 2005 and the avian flu pandemic in 2012 in China, it was realised that trauma response was not sufficient and could be improved. They asked the question how employers and their employees can be better served before, during and after a disaster and acts of terrorism. They conclude that the focus should be more on managing the overall event rather just than reacting to the impact of the event. The focus, therefore, moves more towards what is referred to as CISM.

CISM is described as "a comprehensive, integrative, multi-component crisis intervention system. CISM is considered comprehensive because it consists of multiple crisisintervention components, which functionally span the entire temporal spectrum of a crisis. CISM interventions range from the pre-crisis phase, through to the acute crisis phase, and into the post-crisis phase. CISM is also considered comprehensive in that it 
consists of interventions which may be applied to individuals, small functional groups, large groups, families, organisations, and even communities" (MedicineNet.com).

CISM is the comprehensive approach to managing critical incident stress (CIS). In the context of an employee-employer situation, Robinson (2004:29) mentions that it is a multi-component approach to staff support that incorporates education, individual support, group meetings (including CISD), organisational consultation, family support, referral and follow up.

In addition to the CISM, other psychotherapeutic interventions for post-traumatic stress disorder (PTSD) vary in their emphasis on re-exposure to trauma-related memories and stimuli, cognitive restructuring of the trauma experience, expression and management of emotion, training in stress management (including relaxation training), and general social and vocational support. Although a number of these treatments emphasise one of these components, many combine more than one either implicitly or by design, and relatively few studies dismantled effective components of the psychotherapy (Board on Population Health (BPH), 2008:93).

The EAPA-SA Standards document (2010:11) indicates that one of the standards to consider in designing, implementing and evaluating an EAP is clinical services. As part of an effective EAP's clinical service, trauma management should be offered. The goal of trauma management should be to respond to traumatic situations in time, in agreement with organisational policies and procedures. The objective of trauma management should be to provide trauma-defusing services for the immediately affected employees, to provide debriefing for traumatised employees and to influence policies and procedures relating to trauma management. The motivation for the application of trauma management is to lessen or prevent long-term difficulties or dysfunction for both individual employees and the organisation.

EAPs play a pivotal role in the managing of trauma in the workplace. The fact that EAPA-SA (2010) indicates that trauma management should form part of an EAP's scope of clinical services, as pointed out above, signifies that trauma management forms part of an effective EAP service offering to clients. Trauma management integrates with other services provided by EAPs and assists the company to address problems experienced by individuals and the organisation on various levels. Owing to the expertise of an EAP, the company can ensure that the trauma employees are exposed to assistance, and that impacts on their psycho-social functioning and work performance, are correctly assessed and managed, i.e. through organisational screening, consultation with management, psychological first aid.

\section{ORGANISATIONAL SCREENING}

Prior to a critical incident, the organisation should be assessed in terms of group resilience, adaptive functioning, mutual social support of the group, management support, resources in terms of providing shelter and physical care as well as emotional care, existing structure of dealing with critical incidents and internal role players. The organisational screening should also include a surveillance of potential risk factors. This includes a clinical and organisational assessment of mental health issues, substance 
abuse issues and skills of employees, and identifying all potential medical, organisational and mental health resources to address possible reactions after an incident. The organisational screening should include the assessment of possible threats to an organisation, the level of employee preparedness, the overall health, performance and leadership functions necessary to sustain organisational resilience in the face of disasters or terrorism attacks (Stephenson \& Schneider, 2006:44; Vineburgh et al., 2006:14). EAPs can translate knowledge about appropriate disaster behaviour into workplace health interventions to foster human continuity and organisational resilience.

\section{CONSULTATION WITH MANAGEMENT}

After the organisational screening, management should be informed about the outcome of the organisational screening and possible risks should be highlighted. This gives an idea of the employee population in terms of physical and mental health issues, possible reactions, resources and concerns in the event of a critical incident (Stephenson \& Schneider, 2006:45).

According to Vineburgh et al. (2006:15), this information can assist the EAP to provide a contingency plan for possible critical incidents and disasters. It will further assist management in developing a policy on conduct in such an event, integrating certain professionals (e.g. security) as change agent partners, mobilising a task team and communicating strategy to employees.

\section{PSYCHOLOGICAL FIRST AID (PFA)}

The role of the EAP will also be to explore the efficiency of debriefing and alternative approaches to organisational crisis interventions. Psychological first aid (PFA) is regarded as a favoured alternative approach to CISD and forms an integral part of CISM, as "Psychological first aid (PFA) consists of a systematic set of helping actions aimed at reducing initial post-trauma distress and supporting short- and long-term adaptive functions" (Ruzek, Brymer, Jacobs, Layne, Vernberg \& Watson: 2007:17). VandePol, Gist, Braverman and Labardee (2006:123) add to this that PFA "is by intent a more flexible approach to assessing impacts, determining viable points of productive assistance, and generating helping strategies specifically geared toward the express needs and expectations of the organisation being served and the employees affected. As such it is consultative rather than clinical and advocates assistance rather than intervention."

The role of the EAP is to provide a specialised service or to establish a working relationship with a specialised partner in the field of CISM in order to be in a position to provide the best possible service to the clients. According to VandePol et al. (2006:126128), an EAP with a specialised CISM service or a specialised partner should be able to deliver the following:

- training, information and preparation to inform best practice;

- consultation and assistance with contingency planning;

- access to tools, techniques and instruments; 
- rapid access to trained and capable response staff;

- access to evidence-based tools and techniques for responding beyond the crises situation; and

- evaluation, follow up and impact analysis.

Effective CISM is focused on normalising the abnormal in the quickest possible time to prevent any unnecessary discomfort to the employee, the company and family members, and to restore functioning and productivity.

\section{VALUE OF AN EAP}

The value of an EAP is mostly determined in terms of normalising the reactions employees display after a critical incident and improved psycho-social functioning of the individual, meaning that the focus is on displaying less symptomatic discomfort. Effectiveness of an EAP in this regard is also measured in terms of restoring and stabilising the organisation's employee corps to be fully functional and productive in the quickest possible time. It is usually difficult to measure these factors and to determine the direct impact of an incident and the result of an intervention in the process of restoring the individual's and organisation's functioning, as is confirmed by Attridge and VandePol (2010:140): "The financial - or business case - evidence for supporting CIR (critical incident response) services, however, is not as strong as the evidence for its therapeutic value."

There is, however, evidence from the literature that EAP intervention in terms of critical incidents is effective (Attridge \& VandePol, 2010:133). Critical incident stress response (CIR) refers to an integrated, comprehensive, multi-component crisis intervention approach for addressing the psychological consequences of critical incidents. CIR usually forms part of an EAPs CISM strategy that focuses on the appropriate intervention for a specific critical incident. Over the past 25 years a general model of CIR group debriefing has been developed that can be used to accelerate recovery from traumatic workplace events (VandePol et al., 2006:119). CIR can accomplish psychological closure, prevention and mitigation of traumatic stress, and promote return to normalcy, benefiting the individual, organisation and the community at large.

According to a review by the National Institute of Mental Health (2002:2), "Early, brief, and focused psychotherapeutic intervention can reduce distress in bereaved spouses, parents, and children". What is not a debate anymore, however, is that the use of CISM or other kinds of psychological early interventions cannot successfully prevent the experience of PTSD, according to research by Bryant (2007:22) and Feldner, Monson and Friedman (2007:86), but once someone has developed PTSD or an acute stress disorder, there are treatments with empirical evidence of their clinical efficacy.

Many employers provide access to CIR services because it is the "right thing to do" and thus may not require a formal business case to justify providing the services (Claussen, 2009:49). CIR services are provided primarily to improve the clinical recovery of the individuals affected by the trauma or crisis experience. In the process of this recovery, however, there can also be other outcomes that can benefit the organisation as well. The 
business value for employers of the proper use of CIR services from EAPs is most likely to be found in the outcomes of reduced worker health care costs, reduced disability claim costs, reduced workers' compensation claim costs, reduced worker absence days, and reduced worker turnover because an increasing number of employees can successfully return to work after being on disability after experiencing a traumatic event (Smith \& Rooney, 1999:341). Some businesses provide access to CIR services as a form of risk management and to reduce their legal exposure to workplace-related traumatic incidents (Tehrani, 2002:474).

EAPs strive to improve employee productivity and organisational performance. According to Holtyn (2006:8) and the results of the exclusive return on investment study conducted among wellness managers in America, workplace wellness programmes improve employee morale, reduce company healthcare costs and increase productivity on many levels.

An employee assistance workgroup (EAP workgroup) was established in 2007 in Washington to develop recommendations for improving the coordination and integration of EAPs, as well as examining best practices and evidence-based approaches to design and deliver effective and efficient EAPs (Rothermel, Slavit, Marlo \& Dan, 2008:2). EAPA-SA (2010:1) incorporated this approach by developing certain core technologies and standards as a way of:

- providing a benchmark for employee assistance practice;

- promoting the establishment of quality employee assistance programmes;

- describing the scope of EAP services;

- operationalising programme standards and guidelines;

- educating the workplace community on EAP services to enhance the quality and the functioning of existing employee assistance programmes.

According to Mercer (2007:201), EAPs aligned with an overall health and productivity strategy can perform a critical role in identifying individual and organisational risk factors that may decrease performance. A report by Wyatt (2007:19) suggests that organisational response to health and productivity challenges will increase revenue, market value and shareholder returns.

Rothermel et al. (2008:8) mention that an EAP that is aligned with organisational values and vision measurably enhances business operations, the overall employee experience and the community's perception of the company.

EAPs add value in the following three ways (McLeod \& McLeod, 2001:187; Rothermel et al., 2008:8-9).

1. EAPs leverage the value of the organisation's investment in its workforce by:

- encouraging employee engagement;

- improving employees' and their dependants' abilities to successfully respond to life challenges; 
- offering employees and dependants short-term problem-resolution services or referring them to mental health treatment services;

- developing manager and employee competencies in dealing with workplace stress and improving team performance.

2. EAPs address the cost of doing business by:

- reducing workplace absenteeism and unplanned absence;

- decreasing workplace accidents;

- lowering employee turnover and related replacement costs;

- facilitating safe, timely and effective return-to-work for employees after short-term and extended absence;

- reducing healthcare costs; and

- increasing efficient use of health care through early identification, care management and recovery efforts.

3. EAPs mitigate business risk by:

- reducing the likelihood of workplace violence or other safety risks;

- managing the effect of disruptive incidents in the workplace, such as violence, injury or other crises, and facilitate a swift return-to-work after adverse workplace events;

- supporting disaster and emergency preparedness and minimising disruption after such an event;

- smoothing the adjustment to mergers, acquisitions, site closures or other workforce change events;

- reducing the likelihood of legal action or liability; and

- promoting and supporting drug- and alcohol-free workplace policies and programmes.

According to the American Psychological Association, successful organisations more and more realise that taking care of employees is not only the right thing to do, but it also makes good business sense, as some of the employers demonstrate that investing in employee health and wellbeing leads to business success (Newman, 2007:17).

\section{CONCLUSION AND RECOMMENDATIONS}

Critical incidents are part of employees' daily lives, either by their being exposed to a critical incident themselves, or as a result of a colleague or a family member being exposed. Each individual has certain factors that pertain to the risk and mediate their response to a critical incident.

An EAP plays a pivotal role in managing the reactions to a critical incident and the effect on the individual, the workplace and the family. EAPs provide a framework for effective intervention on different levels to intercede in possible reactions to critical incidents. CISM is a specialised intervention provided within the EAP framework to address the effects of critical incidents on individual employees, employers and families. 
Effective CISM programmes not only add value to the individual employee's life by supporting recovery in the shortest possible time, but also assist families affected by a critical incident to deal with it effectively and also contribute to improving productivity and business effectiveness after a critical incident.

It is recommended that organisations should become more aware of the potential effects of a critical incident in the workplace and understand the importance of instituting effective intervention systems to improve work performance and psychosocial functioning of employees. Increased awareness and understanding in this regard will lead to organisations being more willing to invest in and to support an EAP that can improve the quality of life of their employees and ultimately improve their work performance to the benefit of the employer. By offering CISM services to employees, the organisation gains in terms of increased work performance and business effectiveness.

\section{REFERENCES}

ALTBEKER, A. 2002. Comparing crime in the provinces: trends since 1994. Nedbank ISS Crime Index, 6:7-13.

AMSTADTER, A.B. \& VERNON, L.L. 2008. Emotional reactions during and after trauma: a comparison of trauma types. Journal of Aggression, Maltreatment \& Trauma, 16(4):391-405.

ATTRIDGE, M. \& VANDEPOL, B. 2010. The business case for workplace critical incident response: a literature review and some employer examples. Journal of Workplace Behavioral Health, 25(2)132-145.

BISSON, J.I. 1995. Psychological reactions of victims of violent crime. The British Journal of Psychiatry, 176(6):718-720.

BOARD ON POPULATION HEALTH (BPH). 2008. Treatment of posttraumatic stress disorder: an assessment of the evidence. Washington DC: National Academies Press.

BRENDE, J.O. \& GOLDSMITH, R. 1991. Post-traumatic stress disorder in families. Journal of Contemporary Psychotherapy, 21(2):115-125.

BRUCE, W.M. 1990. Problem employee management. New York: Quaram Books.

BRYANT, R.A. 2007. Early intervention for post-traumatic stress disorder. Early Intervention in Psychiatry, 1(1):19-26.

CARLSON, E.B. 1997. Trauma assessment: a clinicians guide. New York: Guildford. CLAUSSEN, L. 2009. After the incident: how to deliver the message to employees and family members about workplace victims. Safety and Health, (November):48-51.

COMPTON, B.R. \& GALAWAY, B. 1984. Social work processes. Homewood III: Darsey Press. 
DE VRIES, A., KASSAM-ADAMS, N., CNAAN, A., SHERMAN-SLATE, E., GALLAGHER, P. \& WINSTON, F. 1999. Looking beyond the physical injury: posttraumatic stress disorder in children and parents after paediatric traffic injury. Pediatrics, 104(6):1293-1299.

EAPA (South African Chapter). 2010. Standards for employee assistance programs in South Africa. Compiled by: Standards Committee of EAPA-SA.

ENGELBRECHT, A.S. 1997. The impact of crime on the family. Dissertation presented at the Family therapy Michael White Conference. Johannesburg: Helderfontein.

FELDNER, M.T., MONSON, C.M. \& FRIEDMAN, M.J. 2007. A critical analysis of approaches to PTSD prevention. Behavior Modification, 31(1):80-116.

FIGLEY, K.J. 1994. Helping traumatized families. San Francisco: Jossey Bass Publishers.

FRIEDMAN, M.J. 2003. Post-traumatic stress disorder. The latest assessment and treatment strategies. Kansas: Compact Clinicals.

HEINRICHS, M., WAGNER, D., SCHOCH, W., SORAVIA, L.M., HELLHAMMER, D.H. \& EHLERT, U. 2005. Predicting posttraumatic stress symptoms from pretraumatic risk factors: a 2-year prospective follow-up study in fire fighters. The American Journal of Psychiatry, 162(12):2276-2286.

HOLTYN, K. 2006. Wellness program management advisor. Health Resources Publishing.

JANNOF-BULLMAN, R. 1997. Understanding reactions to traumatic events. The Harvard Mental Health Letter Forum, October.

KESSLER, R.C. \& STANG, P.E. (eds). 2006. Health and work productivity: making the business case for quality health care. Chicago: University of Press.

KLEBER, R.J. \& BROM, D. 1992. Coping with trauma: theory, prevention and treatment. Amsterdam: Swets \& Zeitlinger.

LEGGETT, T. 2003. The facts behind the figures. Crime statistics 2002/2003. SA Crime Quarterly, (6): 17.

LEWIS, G.W. 1996. Critical incident stress and trauma in the workplace: recognition, response, and recovery. Accelerated Development Inc. Publishers.

MacGREGOR, J. 1998. The victim's experience of hijacking: a qualitative approach. Johannesburg: Rand Afrikaans University.

McLEOD, J. \& McLEOD, J. 2001. How effective is workplace counselling? A review of the research literature. Counselling Psychotherapy Research, 1(3):184-191.

MedicineNet.com. Retrieved from www.medterms.com. [Accessed: 07/11/2011].

MERCER, M. 2007. Survey of health, productivity and absence management programs. New York: March and McLennan Companies. 
NATIONAL INSTITUTE OF MENTAL HEALTH. 2002. Mental health and mass violence: evidence-based early psychological intervention for victims/survivors of mass violence. A workshop to reach consensus on best practices. NIH Publication No. 02-5138. Washington, DC: U.S. Government Printing Office.

NEWMAN, R. 2007. Top companies show investing in employee health and well-being leads to business success. New Therapist, 49(May/June).

O'BRIEN, L.S. 1998. Traumatic events and mental health. Cambridge: Cambridge University Press.

O'CONNER, J. \& JEAVONS, S. 2002. Nurses perceptions of critical incidents. Issues and Innovations in Nursing Practice, 53-62.

RIBNER, D.S. 1993. Crisis in the workplace: the role of the occupational social worker. MaatskaplikeWerk/Social Work, 38(3):333-338.

ROBINSON, R. 2004. Counterbalancing misinterpretations of critical incident stress debriefing and critical incident stress management. Australian Psychologist, 39(1):2934.

ROTHERMEL, S., SLAVIT, W., MARLO, K. \& DAN, D. 2008. An employer's guide to employee assistance programs: recommendations for strategically defining, integrating and measuring employee assistance programs. Washington DC: Center for Prevention and Health Services.

RUZEK, J.I., BRYMER, M., JACOBS, A.K., LAYNE, C.M., VERNBERG, E.M. \& WATSON, P.J. 2007. Psychological first aid. Journal of Mental Counseling, 29(1):1749.

SACK, W., CLARKE, G. \& SEELEY, J. 1995. Post-traumatic stress disorder across two generations of Cambodian refugees. Journal of the American Academy of Child \& Adolescent Psychiatry, 34(9):1160-1166.

SHALEV, A.Y., FREEMAN, S., PERI, T., BRANDES, D., SAHAR, T., ORR, S. \& PITMAN, R. 1998. Prospective study of post-traumatic stress disorder and depression following trauma. American Journal of Psychiatry, 155:630-673.

SCHUlZ, H., VAN WIJK, T. \& JONES, P. 2000. Trauma in Southern Africa. Understanding emotional trauma and aiding recovery. Traumatology Services International.

SMITH, E. 2005. Trauma and family. [Online] Available: www.betterhealth.co.au [Accessed: 11/07/2011].

SMITH, G.B. \& ROONEY, T. 1999. EAP intervention with workers' compensation and disability management. In: OHER, J. (ed), The Employee Assistance Handbook. NY: Wiley.

SONDERUP, 1996. When trauma comes to the door. People Dynamics, September, 12. 
SOUTH AFRICAN POLICE SERVICES. 2012. Crime Statistics. [Online] Available: http://www.saps.gov.za/statistics/reports/crimestats/2012/downloads/crime_statistics_pr esentation.pdf (Accessed: 18/02/2013].

STEPHENSON, D. \& SCHNEIDER, D.U. 2006. Case studies of federal occupational health's EAP responses to natural disasters. Journal of Workplace Behavioral Health, 21(3\&4):35-38.

TEDESCHI, R.G. \& CALHOUN, L.G. 1995. Trauma and transformation: growing in the aftermath of suffering. London: Sage Publications.

TEHRANI, N. 2002. Workplace trauma and the law. Journal of Traumatic Stress, 15(6):473-477.

VAN DER KOLK, B.A. 1991. The psychological processing of traumatic events: the personal experience of post-traumatic stress disorder. In: REESE, J., HORN, J. \& DUNNING, C. (eds) Critical incidents in policing. Washington DC: US Government.

VAN DER KOLK, B.A. \& McFARLANE, A.C. 1996. Traumatic stress: the effects of an overwhelming experience on mind, body and society. New York: Guilford Press.

VANDEPOL, B., GIST, R., BRAVERMAN, M. \& LABARDEE, L. 2006. Strategic specialty partnerships: Enabling the EAP for evidence informed best practices in workplace crisis response. Journal of Workplace Behavioral Health, 21(3/4):119-131.

VINEBURGH, N.T., URSANO, R.J., GIFFORD, R.K., BENEDEK, D. \& FULLERTON, C.S. 2006. Disaster preparedness in the $21^{\text {st }}$ century. Journal of Employee Assistance, 36(4):14-17.

WHITE, M. \& EPSON, D. 1990. Narrative means to therapeutic end. New York: W.W. Norton \& Company.

WILSON, J.P. 1989. Trauma, transforming and healing: An integrative approach to theory, research and post-traumatic therapy. New York: Brunner \& Mazel.

WYATT, W. 2007. Staying at work report, building an effective health and productivity network. Washington, DC: Watson Wyatt Worldwide.

YEHUDA, R. 2002. Post-traumatic stress disorder. The New England Journal of Medicine, 346(2):108-113.

Prof Lourie Terblanche, Department of Social Work and Criminology, University of Pretoria; Dr André van Wyk, doctoral student, Department of Social Work and Criminology, University of Pretoria, Pretoria, South Africa. 